J. S. DEHOVITZ, Y. Y. LOH, J. A. KAUTZKY, K. NAGAO, A. J. MEICHAN, M. YAMAUCHI, D. W. C. MACMILLAN*, T. K. HYSTER* (PRINCETON UNIVERSITY, USA)

Static to Inducibly Dynamic Stereocontrol: The Convergent Use of Racemic $\beta$-Substituted Ketones Science 2020, 369, 1113-1118, DOI: 10.1126/science.abc9909.

\section{Chemoenzymatic Dynamic Kinetic Resolution at Normally Static Stereogenic Centers}<smiles>[C]C1CCCCC1</smiles>

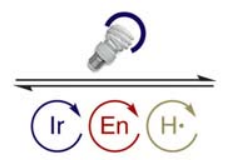

photoredox-catalyzed racemization

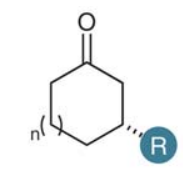

$\mathrm{R}=\mathrm{Alk}$, (Het)Ar $\mathrm{n}=0$ or 1
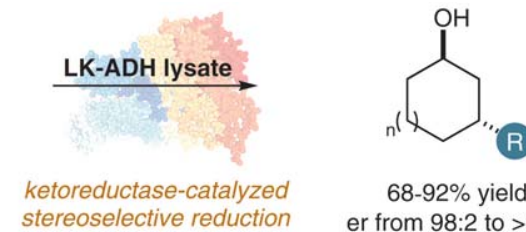

$68-92 \%$ yield er from $98: 2$ to $>99: 1$ dr from $5: 1$ to $>20: 1$
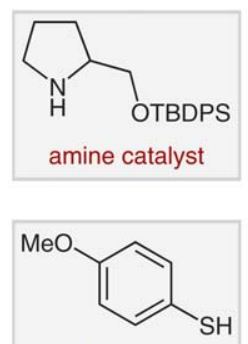

thiol catalyst overall: chemoenzymatic dynamic kinetic resolution (DKR)

$$
\begin{gathered}
\text { Conditions: } \\
\text { amine catalyst }(20 \mathrm{~mol} \%) \\
\text { thiol catalyst }(10 \mathrm{~mol} \%) \\
{[\mathrm{Ir}] \text { catalyst }(1 \mathrm{~mol} \%)} \\
\text { LK-ADK lysate }(0.24 \mathrm{~mol} \%) \\
\text { NADP }(0.67 \mathrm{~mol} \%), i-P r O H(11 \% \mathrm{v} / \mathrm{v}) \\
50 \mathrm{mM} \mathrm{KPi} \mathrm{buffer} \mathrm{pH} 7.5(0.017 \mathrm{mM}) \\
\text { r.t., } 18 \mathrm{~h} \text {, blue LED }
\end{gathered}
$$

\section{Category}

Organo- and

Biocatalysis

Key words

photoredox catalysis

aminocatalysis

ketoreductase

dynamic kinetic resolution

alcohols

stereoconvergent synthesis

\section{Syniact of the Month}

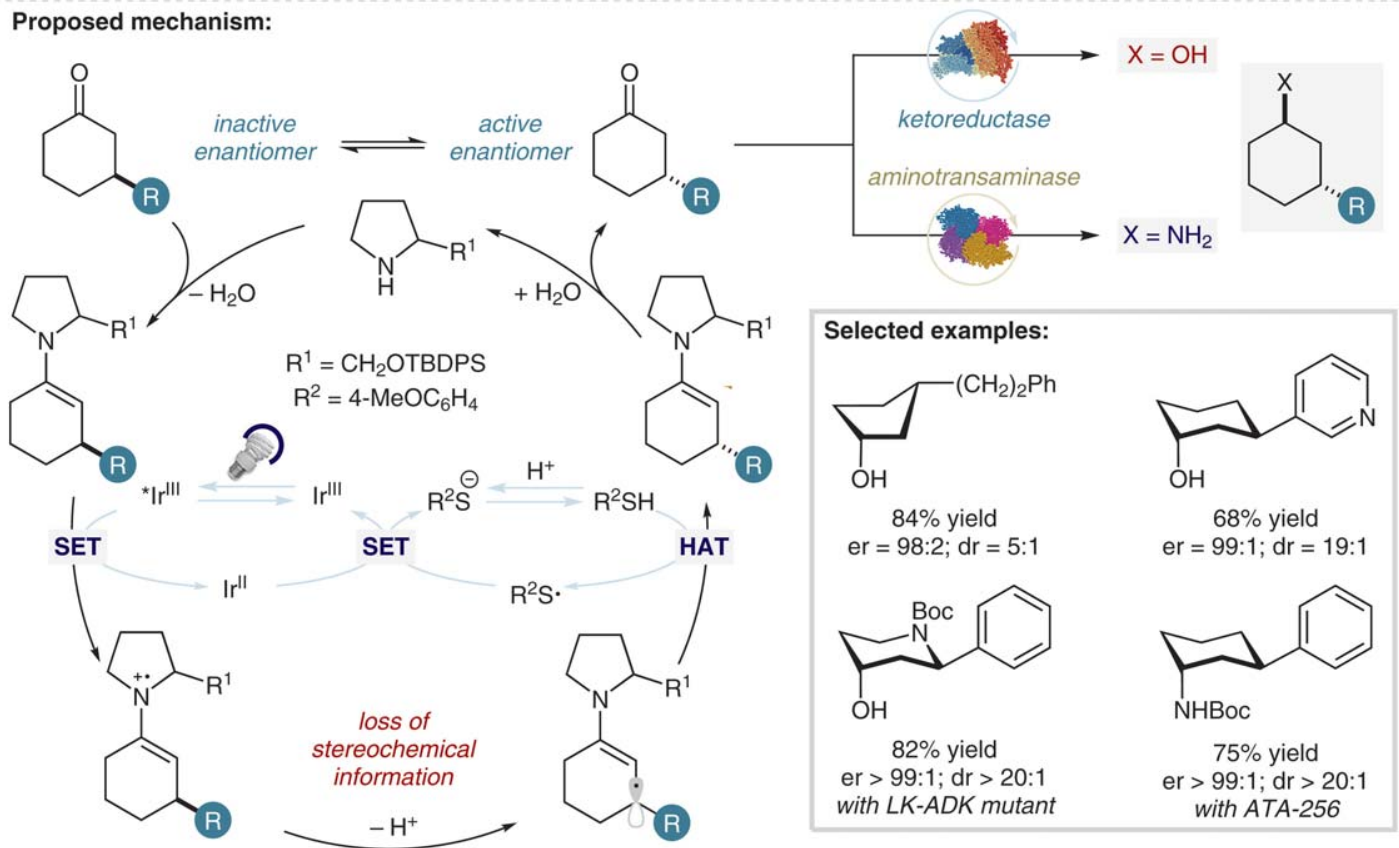

Significance: The Hyster and MacMillan groups used photoredox catalysis to induce dynamic stereocontrol at normally static stereogenic centers and, in conjunction with a ketoreductase, yield $\gamma$-substituted alcohols in nearly enantiopure form.
Comment: Given the range of chemical space that is open to photo-/organocatalytic processes, paired with the unparalleled selectivity of enzymes, this novel platform will undoubtedly open new pathways for stereoconvergent syntheses. 